\title{
Twelve Key Findings in Deliberative Democracy Research
}

\author{
Nicole Curato, John S. Dryzek, Selen A. Ercan, \\ Carolyn M. Hendriks \& Simon Niemeyer
}

Abstract: This essay reflects on the development of the field of deliberative democracy by discussing twelve key findings that capture a number of resolved issues in normative theory, conceptual clarification, and associated empirical results. We argue that these findings deserve to be more widely recognized and viewed as a foundation for future practice and research. We draw on our own research and that of others in the field.

NICOLE CURATO is Australian Research Council Discovery Early Career Research Fellow at the University of Canberra.

JOHN S. DRYZEK is Australian Research Council Laureate Fellow and Centenary Professor at the University of Canberra.

SELEN A. ERCAN is Senior Research Fellow at the University of Canberra.

CAROLYN M. HENDRIKS is Associate Professor at the Australian National University.

SIMON NIEMEYER is Australian Research Council Future Fellow at the University of Canberra.

( "See endnotes for complete contributor biographies.)
$\mathrm{D}$ eliberative democracy is a normative project grounded in political theory. And political theorists make a living in large part by disagreeing with and criticizing each other. In fact, it is possible to evaluate the success of a political theory by the number of critics it attracts, and the vitality of its intramural disputes. By this measure, deliberative democracy is very successful indeed. Yet if the normative project is to progress and be applied effectively in practice, it needs to lay some issues to rest.

Deliberative democracy is not just the area of contention that its standing as a normative political theory would suggest. It is also home to a large volume of empirical social science research that, at its best, proceeds in dialogue with the normative theory. Indeed, the field is exemplary in this combination of political theory and empirical research. Deliberative ideas have also attracted the attention of citizens, activists, reform organizations, and decision-makers around the world. The practical uptake of deliberative ideas in political innovation provides a rich source of lessons from experience that can be added to theorizing and social science. This combination has proven extremely fruitful. Rather than proving or falsi-

(C) 2017 by the American Academy of Arts \& Sciences doi:10.1162/DAED_a_00444 
fying key hypotheses, deliberative practice has sharpened the focus of the normative project, showing how it can be applied in many different contexts.

Webelieve that conceptual analysis, logic, empirical study, normative theorizing, and the refinement of deliberative practice have set at least some controversies to rest, and we provide the following set of twelve key findings that can be used as the basis for further developments.

\section{Deliberative democracy is realistic. Skeptics} have questioned the practical viability of deliberative democracy: its ideals have been criticized as utopian and its forums have been dismissed as mere experiments, with no hope of being institutionalized effectively. ${ }^{1}$

But skeptics have been proved wrong by the many and diverse deliberative innovations that have been implemented in a variety of political systems. ${ }^{2}$ Both state and nonstate institutions demand more deliberative forms of citizen engagement. Policymakers and politicians convene citizens' forums to elicit informed views on particular issues. ${ }^{3}$ Studies find that deliberating citizens can and do influence policies, though impacts vary and can be indirect. ${ }^{4}$ Deliberative forums are also being implemented in parliamentary and electoral contexts. ${ }^{5}$ Outside the state, citizen forums are funded and implemented variously by civil society organizations, think tanks, corporations, and international organizations to advance a particular cause, foster public debate, or promote democratic reform. ${ }^{6}$

The recent turn toward deliberative systems demonstrates that deliberative democratic ideals can be pursued on a large scale in ways that link particular forums and more informal practices, such as communication in old and new media. ${ }^{7}$ Deliberative democracy is not utopian; it is already implemented within, outside, and across governmental institutions worldwide.
Deliberation is essential to democracy. Social choice theory appears to demonstrate that democratic politics must be plagued by arbitrariness and instability in collective decision. Notably, for political scientist William Riker, clever politicians can manipulate agendas and the order in which votes are taken to ensure their preferred option wins. ${ }^{8}$ But if their opponents are also clever, they can do the same. And in that case, there can be no stable will of the people that can possibly be revealed by voting (in, say, a legislature). So, how can meaning and stability be restored to democracy? There are essentially two mechanisms, once dictatorship is ruled out. The first is what rational choice theorist Kenneth Shepsle calls "structure induced equilibrium," under which formal rules and informal understandings restrict strategizing, including the ability to manipulate agendas and the order in which votes are taken. ${ }^{9}$ The second is deliberation.

Political theorist David Miller and, later, John Dryzek and political philosopher Christian List have demonstrated formally that deliberation can, among other responses:1) induce agreement to restrict the ability of actors to introduce new options that destabilize the decision process and 2) structure the preferences of participants such that they become "single-peaked" along one dimension, thus reducing the prevalence of manipulable cycles across alternatives (in which option A beats $\mathrm{B}$ in a majority vote, $B$ beats $C$, and $C$ beats $A) .{ }^{10}$ Empirical research confirms this effect. ${ }^{11}$

This result explains why all democratic settings, in practice, feature some combination of communication, which can be more or less deliberative, and formal and informal rules. The more deliberative the communication, the better democracy works. Democracy must be deliberative.

Deliberation is more than discussion. Deliberative democracy is talk-centric. But talk alone can be pathological, producing wildly mixed results from an ideal deliberative
Nicole Curato, John S. Dryzek, Selen A. Ercan, Carolyn $M$. Hendriks \& Simon Niemeyer 
Twelve Key Findings in Deliberative Democracy Research perspective. ${ }^{12}$ Resolution here requires distinguishing carefully between deliberation and discussion.

Empirical observation reveals that deliberation is more complex than originally theorized, involving both dispositional and procedural components. The purely procedural rationalist model of deliberation is normatively problematic because it is empirically questionable. ${ }^{13}$ Distinguishing between deliberation and discussion introduces an emotional dimension in which dispositional factors, such as open-mindedness, are important. ${ }^{14}$

The overall content of this disposition has more recently been referred to as the "deliberative stance," which political theorists David Owen and Graham Smith have defined as "a relation to others as equals engaged in mutual exchange of reasons oriented as if to reaching a shared practical judgement." 15 Achieving a deliberative stance in citizen deliberation involves careful facilitation and attention to "emotional interaction." 16 Its achievement in group settings can be a pleasurable experience and consistent with ideals of human cognition. ${ }^{17}$ Scaling these effects up to the wider deliberative system requires careful attention to institutional settings. ${ }^{18}$

Deliberative democracy involves multiple sorts of communication. Some democrats have charged deliberative democracy with being overly rationalistic. For political scientist Lynn Sanders, deliberation works undemocratically for it excludes "those who are less likely to present their arguments in ways that we recognize as characteristically deliberative." 19 Sanders refers to women, racial minorities, and the poor, whose speech cultures depart from "rationalist" forms of discourse that privilege dispassionate argumentation, logical coherence, and evidence-based claims as practiced in the most exclusive kinds of scholarly debates, parliamentary procedures, and judicial argumentation. A similar kind of cri- tique has been raised by political theorist Chantal Mouffe, who criticizes deliberative democrats for missing the crucial role that passion plays in politics and for emphasizing the rationalism of liberal democratic political thought. ${ }^{20}$

Deliberative democrats have responded by foregrounding the varied articulations of reason-giving and consensus requirements of deliberation. Most have acknowledged political philosopher Iris Young's conception of "communicative democracy" and have conditionally embraced greeting, rhetoric, humor, testimonies, storytelling, and other sorts of communication. ${ }^{21}$ Even the originally somewhat rationalistic criteria of the widely used Discourse Quality Index have evolved to include storytelling as one indicator, recognizing the importance of personal narratives in political claim-making. ${ }^{22}$ Recent developments in deliberative theory have begun to recognize the plurality of speech cultures. The turn to deliberative systems has emphasized multiple sites of communication, each of which can host various forms of speech that can enrich the inclusive character of a deliberative system. The increasing attention paid to deliberative cultures is also part of this trajectory, in which systems of meanings and norms in diverse cultural contexts are unpacked to understand the different ways political agents take part in deliberative politics. ${ }^{23}$

Deliberation is for all. The charge of elitism was one of the earliest criticisms of deliberative democratic theory: that only privileged, educated citizens have access to the language and procedures of deliberation. However, empirical research has established the inclusive, rather than elitist, character of deliberative democracy.

Findings in deliberative experiments suggest that deliberation can temper rather than reinforce elite power. Political scientists James Druckman and Kjersten Nelson have shown how citizen conversations can vitiate the influence of elite framing. ${ }^{24}$ 
Simon Niemeyer has shown how deliberative mini-publics, such as citizens' juries (composed of a relatively small number of lay citizens), can see through "symbolic politics" and elite manipulation of public discourse through spin doctoring. ${ }^{25}$ Realworld deliberative processes provide considerable evidence on deliberation's potential to build capacities of traditionally marginalized groups. Economist Vijayendra Rao and sociologist Paromita Sanyal's work on gram sabhas in South India is a landmark study, demonstrating village-level deliberations' capacity to mobilize civic agency among the poor, counteracting resource scarcity and social stratification. ${ }^{26}$ Brazil's National Public Policy Conferences - one of the biggest nationally successful exercises in public deliberation - illustrate how ordinary citizens influence public policy once they acquire the opportunity to take part in consequential deliberation. ${ }^{27}$

These examples illustrate deliberative democracy's record in curtailing, rather than perpetuating, elite domination by creating space for ordinary political actors to create, contest, and reflect upon ideas, options, and discourses.

Deliberative democracy has a nuanced view of power. Early critics of deliberative democracy worried about its political naiveté, particularly its neglect of power and strategy. ${ }^{28}$ However, deliberative democracy is not naive about power, but rather has a nuanced approach to it.

In the deliberative ideal, coercive forms of power, defined as the threat of sanction or use of force against another's interests, are absent because they distort communication. ${ }^{29}$ But deliberative practice reveals that coercive power is ubiquitous: it pervades the very process of argumentation and communication, affects the remit and organization of deliberative procedures, and shapes the broader policy context. ${ }^{30}$ Procedural designs can, however, limit coercive power by, for example, selecting participants that are less partisan, using independent facilitators, or ensuring deliberations are public.

Empowering or generative forms of power are central to the communicative force of deliberative governance. ${ }^{31}$ Authoritative power is also necessary for deliberative democracy, which requires leaders who are receptive to the concerns of affected publics and have the legitimate authority to consider and act on the public's preferences and concerns. ${ }^{32}$ Actors in and around deliberative processes can also strategize to advance agendas and address inequalities. ${ }^{33}$

Deliberative democrats recognize that coercive power pervades social relations, but understand that certain kinds of power are needed to maintain order in a deliberative process, to address inequalities, and to implement decisions. ${ }^{34}$

Productive deliberation is plural, not consensual. A seeming commitment to the pursuit of consensus - that is, agreement on both a course of action and the reasons for it once provided a target for critics of deliberative democracy, who stressed its otherworldly character and silencing of dissident voices. ${ }^{35}$ However, contrary to these arguments, deliberative democrats have rarely endorsed consensus as an aspiration for real-world decision-making (as opposed to one theoretical reference point).

Decision-making in deliberative democracy can involve voting, negotiation, or workable agreements that entail agreement on a course of action, but not on the reasons for it. All of these benefit from deliberation, which can involve clarification of the sources of disagreement, and understanding the reasons of others. Rather than consensus, deliberation should recognize pluralism and strive for metaconsensus, which involves mutual recognition of the legitimacy of the different values, preferences, judgments, and discourses held by other participants. ${ }^{36}$ 
Twelve Key Findings in Deliberative Democracy Research
At first sight, this acceptance of pluralism and metaconsensus might seem to contradict the findings of political scientist Jürg Steiner and colleagues that the more consensual a system of government, the better the quality of deliberation that occurs in its legislature. Consensual democracies - notably the Nordic countries, The Netherlands, Germany, and Switzerland are also arguably the world's most successful states on a variety of indicators, suggesting a strong correlation between deliberation and public policy success, though correlation here does not necessarily imply causality. However, the concept of consensual liberal democratic states (as opposed to adversarial) does not imply consensus in the strong sense we identified. Consensual states are still pluralistic, but their pluralism is channeled into workable agreements, not adversarial point-scoring.

Participation and deliberation go together. A sharp distinction between participation and deliberation is drawn by political theorist Carole Pateman, who argues that deliberative democrats have shown "little interest in the last thirty years of participatory promotion" and instead focus on mini-publics or "new deliberative bodies."37

This distinction misfires. First, while it is true that a large number of deliberative scholars research mini-publics, these studies are motivated by the desire to better understand how lessons learned from smallscale deliberative forums can be scaled up to mass democracies and enhance the quality of political participation. So, for example, John Dryzek and ecological economist Alex Lo have shown how particular rhetorical moves can increase the quality of reasoning in a mini-public, which has direct implications for how climate change should be communicated in the public sphere (further examples will be provided in our discussions of time, group polarization, and divided societies). ${ }^{38}$ Mini-publics, in other words, are not valorized as democratic practice par excellence, but rather are used as a tool to democratize other facets of political life and deepen the quality of political participation.

Second, the political projects of participatory and deliberative democracy are intimately linked. Pateman's aspirations for a “participatory society," in which various aspects of our social and political lives are democratized, are not distinct from deliberative democrats' vision of a society in which all citizens affected by a decision have capacities and opportunities to deliberate in the public sphere. ${ }^{39}$ This has been articulated by "macro" deliberative theorists, whose focus is to improve the quality of political participation in the public sphere, whether online or offline, mediated or face-to-face, such that citizens can affect political processes on issues they care about.

Deliberative transformation takes time. Deliberation by definition requires amenability to preference transformation, but such transformation may not be a good measure of the quality of deliberation. ${ }^{40}$ While large changes in preferences can occur early in deliberative processes, this change can reflect anticipation of absorbing information and group deliberation as much as the effect of deliberation proper. ${ }^{41}$

The goal of deliberation is for citizens to determine reflectively not only preferences, but also the reasons that support them. ${ }^{42}$ As we have already noted, at the group level, this involves the formation of a kind of metaconsensus featuring mutual recognition of the manner in which beliefs and values map onto preferences. ${ }^{43}$

This process takes time and deliberation does not necessarily follow a smooth path. Initial changes to preferences can even be partially reversed. The initial opening up of minds (as part of taking a deliberative stance) and uptake of information represents a dramatic threshold in the transition toward deliberation proper, producing changes that represent catharsis as much as 
deliberation. It is subsequent reflection that produces deliberative preferences, only after the stance is achieved. ${ }^{44}$ Consequently, reported results from very short deliberative processes may only reflect the path toward, rather than the result of, deliberation. True deliberative transformation takes longer than that.

Deliberation is the solution to group polarization. Cass Sunstein has claimed that a "law of group polarization" causes "deliberative trouble." 45 For if a group is made up of people whose opinions range from moderate to extreme on an issue, after deliberation, the group's average position will be closer to the extreme. Thus, deliberation leads to unhealthy political polarization. There are three reasons why deliberative democracy does not succumb to this.

First, polarization depends crucially on group homogeneity, in which initial opinions vary from moderate to extreme in a single direction, such as the degree of denial of climate science or the degree of support for public education. For anyone designing a deliberative forum, the solution is simple: make sure there are participants from different sides on an issue. James Fishkin says this is exactly how his deliberative opinion polls resist polarization: a random selection of participants ensures a variety of initial views. ${ }^{46}$

Second, what Sunstein describes as polarization could, in many cases, be described as clarity. This is especially important for oppressed groups struggling to find a voice. ${ }^{47}$ Talk with like-minded others can give people, individually and collectively, the confidence subsequently to enter the larger public sphere; enclave deliberation can have positive effects in the deliberative system.

Third, political scientist Kimmo Grönlund and colleagues have demonstrated that polarization only applies under unstructured conversation $;{ }^{48}$ polarization is not found when groups are run on standard deliberative principles with a facilitator.
Their experiment involved citizens deliberating immigration in Finland, and after deliberation, a group that was moderately to extremely hostile to immigrants shifted toward a generally more tolerant opinion. After unstructured discussion, a similar group was, on average, more extreme. Deliberation does, then, provide solutions to group polarization, most obviously when it moves beyond unstructured discussion.

Deliberative democracy applies to deeply divided societies. Deeply divided societies characterized by mutually exclusive religious, national, racial, or ethnic identity claims challenge any kind of democratic politics, including deliberative politics, which some skeptics believe belongs only in more orderly and less fraught settings. Popular political solutions for deeply divided societies instead involve power-sharing negotiated by elites from different blocs, leaving no space for public deliberation (indeed, communication of any sort) across the divide. 49

There is, however, growing empirical evidence showing that deliberative practices can flourish in deeply divided societies to good effect, be it in association with, or at some distance from, power-sharing arrangements. Evidence comes from formats ranging from mixed-identity discussion groups located in civil society to more structured citizen forums with participants from different sides..$^{50}$ Mini-public experiments on deeply divided societies, for example, generate crucial lessons on how conversations in the public sphere can be organized in such a way that they aid in forging mutual respect and understanding across discursive enclaves. As political scientist Robert Luskin and colleagues have noted, once assembled, conflicting groups in divided societies can "have enough in common to permit meaningful and constructive deliberation." ${ }^{1}$ Such deliberation can promote recognition, mutual understanding, social learning about the other side, and even solidarity across deep differences. ${ }^{52}$ 
Twelve Key Findings in

Deliberative

Democracy Research
Deliberative processes have been applied in divided societies such as South Africa, Turkey, Bosnia, Belgium, and Northern Ireland. Given the depth of the disagreement among conflicting groups, deliberative practices do not seek or yield consensus (understood as universal agreement both on a course of action and the reasons for it), but they play a crucial role in terms of "working agreements" across the parties to a conflict. Under the right conditions, deliberation in divided societies can help to bridge the deep conflicts across religious, national, racial, and ethnic lines.

Deliberative research productively deploys diverse methods. Standard social science methods, such as surveys and psychological experiments, are often used to study deliberation. However, they do not do full justice to the ability of deliberators to develop their own understanding of contexts, which can extend to the kinds of social science instruments that are appropriate and to questions that should be asked. Standard methods have a hard time capturing these dynamic aspects of deliberative opinion formation, and they tell us nothing about the broader political or social context in which public deliberation occurs. ${ }^{53}$

Innovative quantitative methods have been developed to remedy these shortcomings: 54 they can involve analyzing the content of deliberations to assess deliberative practice against normative standards, to measure the quality of deliberation, and to evaluate the intersubjective consistency of deliberators across preferences and values. ${ }^{55}$ Qualitative and interpretive methods have also generated empirical insights into public deliberation, particularly through in-depth case studies. Methods such as in-depth interviews and observation have been used to examine the views and behavior of political actors in and around deliberative forums. ${ }^{56}$ Frame and narrative analysis have been used to map discourses and analyze the communicative dynamics of deliberative systems. ${ }^{57}$

Deliberative democracy scholars deploy multiple research methods to shed light on diverse aspects of public deliberation in practice. Those who insist on using conventional social science methods must recognize that their results should be interpreted in light of this broader array of methods and the breadth of understanding so enabled.

$\mathrm{W}_{\mathrm{e}}$ have surveyed what we believe to be a number of key resolved issues in the theory, study, and practice of deliberative democracy. In a number of cases, we have replied to critics skeptical of the desirability, possibility, and applicability of deliberative democracy. Our intent is not, however, to silence critics. Rather, we hope that their efforts can be more tightly focused on the real vulnerabilities of the project, rather than its imagined or discarded features. However, we suspect that, in practice, our summary of key findings will be more useful to those seeking to advance or study the project, rather than those trying to refute it. For these scholars and practitioners, identifying the resolved issues will leave them free to concentrate on unresolved issues. 
* Contributor Biographies: NICOLE CURATO is Australian Research Council Discovery Early Career Research Fellow at the Institute for Governance and Policy Analysis at the University of Canberra, Australia. She has published articles in such journals as Policy Sciences, Policy Studies, and European Political Science Review.

JOHN S. DRYZEK is Australian Research Council Laureate Fellow and Centenary Professor in John S. Dryzek, Selen A. Ercan, Carolyn $M$. Hendriks \& Simon Niemeyer the Centre for Deliberative Democracy and Global Governance at the Institute for Governance and Policy Analysis at the University of Canberra, Australia. His recent books include Democratizing Global Climate Governance (with Hayley Stevenson, 2014), Climate-Challenged Society (with Richard B. Norgaard and David Schlosberg, 2013), and The Politics of the Earth: Environmental Discourses (third edition, 2013).

SELEN A. ERCAN is Senior Research Fellow at the Centre for Deliberative Democracy and Global Governance at the Institute for Governance and Policy Analysis at the University of Canberra, Australia. She has published articles in such journals as International Political Science Review, Policy and Politics, Australian Journal of Political Science, and Critical Policy Studies.

CAROLYN M. HENDRIKS is Associate Professor at the Crawford School of Public Policy at the Australian National University. She is the author of The Politics of Public Deliberation: Citizen Engagement and Interest Advocacy (2011) and has published in such journals as Politics \& Society, Political Studies, and European Journal of Political Research.

SIMON NIEMEYER is Australian Research Council Future Fellow at the Institute for Governance and Policy Analysis at the University of Canberra, Australia. He has published articles in such journals as American Political Science Review, Politics \& Society, Ethical Perspectives, and Australian Journal of Politics and History.

${ }^{1}$ John Mueller, Capitalism, Democracy, and Ralph's Pretty Good Grocery (Princeton, N.J. : Princeton University Press, 1999); and Daniel A. Bell, "Democratic Deliberation: The Problem of Implementation," in Deliberative Politics: Essays on Democracy and Disagreement, ed. Stephen Macedo (Oxford: Oxford University Press, 1999), 71-87.

${ }^{2}$ Stephen A. Coleman, Anna Przybylska, and Yves Sintomer, eds., Deliberation and Democracy: Innovative Processes and Institutions (New York: Peter Lang, 2015).

3 Tina Nabatchi, John Gastil, G. Michael Weiksner, and Matt Leighninger, eds., Democracy in Motion: Evaluating the Practice and Impact of Deliberative Civic Engagement (Oxford: Oxford University Press, 2012).

${ }^{4}$ Gregory Barrett, Miriam Wyman, and Vera Schatten, "Assessing Policy Impacts of Deliberative Civic Engagement," in ibid., 181-203.

5 Carolyn M. Hendriks, "Coupling Citizens and Elites in Deliberative Systems: The Role of Institutional Design,” European Journal of Political Research 55 (1) (2016): 43-60.

6 See Nabatchi et al., Democracy in Motion.

7 John Parkinson and Jane Mansbridge, eds., Deliberative Systems: Deliberative Democracy at the Large Scale (Cambridge: Cambridge University Press, 2012).

8 William H. Riker, Liberalism Against Populism: A Confrontation Between the Theory of Democracy and the Theory of Social Choice (San Francisco: W. H. Freeman and Company, 1982).

9 Kenneth A. Shepsle, "Institutional Agreements and Equilibrium in Multidimensional Voting Models," American Journal of Political Science 23 (1) (1979): 27 - 59.

10 David Miller, "Deliberative Democracy and Social Choice," Political Studies 40 (1) (1992): 54 67 ; and John S. Dryzek and Christian List, "Social Choice Theory and Deliberative Democracy: A Reconciliation," British Journal of Political Science 33 (1) (2003): 1- 23.

${ }^{11}$ Christian List, Robert C. Luskin, James S. Fishkin, and Iain McLean, "Deliberation, Single-Peakedness, and the Possibility of Meaningful Democracy," Journal of Politics 75 (1) (2013): 80 - 95. 
Twelve Key Findings in Deliberative Democracy Research

12 Tali Mendelberg, “The Deliberative Citizen : Theory and Evidence,” in Political Decision Making, Deliberation and Participation: Research in Micropolitics, vol. 6, ed. Michael X. Delli Carpini, Leonie Huddy, and Robert Y. Shapiro (Greenwich, Conn. : JAI Press, 2002), 151-193.

${ }^{13}$ Iris Marion Young, "Justice, Inclusion, and Deliberative Democracy," in Deliberative Politics, ed. Macedo, $151-158$.

${ }^{14}$ George Loewenstein, Ted O’Donoughue, and Sudeep Bhatia, "Modelling the Interplay Between Affect and Deliberation," Decision 2 (2) (2015): 55 - 81; and Jason Barabas, "How Deliberation Affects Policy Opinions," American Political Science Review 98 (4) (2004): 687-701.

15 David Owen and Graham Smith, "Survey Article: Deliberation, Democracy, and the Systemic Turn," Journal of Political Philosophy 23 (2) (2015): 228.

${ }^{16}$ Jane Mansbridge, Janette Hartz-Karp, Matthew Amengual, and John Gastil, "Norms of Deliberation: An Inductive Study," Journal of Public Deliberation 2 (1) (2006).

17 Hugo Mercier and Hélène E. Landemore, "Reasoning is for Arguing: Understanding the Successes and Failures of Deliberation," Political Psychology 33 (2) (2012): 243-258.

${ }^{18}$ Simon J. Niemeyer, "Scaling Up Deliberation to Mass Publics: Harnessing Mini-Publics in a Deliberative System," in Deliberative Mini-Publics: Practices, Promises, Pitfalls, ed. Kimmo Grönlund, André Bächtiger, and Maija Setälä (Colchester, United Kingdom: ECPR Press, 2014).

19 Lynn M. Sanders, “Against Deliberation,” Political Theory 25 (3) (1997): 349.

${ }^{20}$ Chantal Mouffe, "Politics and Passions: The Stakes of Democracy," Ethical Perspectives 7 (2/3) (2000): $146-150$.

${ }^{21}$ Iris Marion Young, "Difference as a Resource for Democratic Communication," in Deliberative Democracy: Essays on Reason and Politics, ed. James F. Bohman and William Rehg (Cambridge, Mass.: The MIT Press, 1997), 383-406.

22 Jürg Steiner, André Bächtiger, Markus Spörndli, and Marco Steenbergen, Deliberative Politics in Action: Analyzing Parliamentary Discourse (Cambridge: Cambridge University Press, 2004).

${ }^{23}$ Jensen Sass and John S. Dryzek, "Deliberative Cultures," Political Theory 42 (1) (2014): 3-25.

${ }^{24}$ James N. Druckman and Kjersten R. Nelson, “Framing and Deliberation : How Citizens' Conversations Limit Elite Influence," American Journal of Political Science 47 (4) (2003): 729 - 745.

25 Simon J. Niemeyer, "The Emancipatory Effect of Deliberation: Empirical Lessons from Mini-Publics," Politics \& Society 39 (1) (2011): 103-140.

${ }^{26}$ Vijayendra Rao and Paromita Sanyal, "Dignity Through Discourse : Poverty and the Culture of Deliberation in Indian Village Democracies," The Annals of the American Academy of Political and Social Science 629 (1) (2010): 146-172.

27 Thamy Pogrebinschi and David Samuels, "The Impact of Participatory Democracy: Evidence from Brazil’s National Public Policy Conferences," Comparative Politics 46 (2014): 313-332.

${ }^{28}$ Ian Shapiro, "Enough of Deliberation : Politics is About Interests and Power," in Deliberative Politics, ed. Macedo, $28-38$.

29 Jane Mansbridge, James Bohman, Simone Chambers, et al., “The Place of Self-Interest and the Role of Power in Deliberative Democracy," Journal of Political Philosophy 18 (1) (2010): 64-100.

30 Carolyn M. Hendriks, "Deliberative Governance in the Context of Power," Policy and Society 28 (3) (2009): $173-184$.

${ }^{31}$ Ibid.

${ }^{32}$ Jonathan W. Kuyper, "Deliberative Democracy and the Neglected Dimension of Leadership," Journal of Public Deliberation 8 (1) (2012).

33 Jennifer Dodge, "Environmental Justice and Deliberative Democracy: How Social Change Organizations Respond to Power in the Deliberative System," Policy and Society 28 (3) (2009): $225-239$. 
34 See Mansbridge et al., “The Place of Self-Interest and the Role of Power in Deliberative Democracy."

35 Iris Marion Young, "Communication and the Other: Beyond Deliberative Democracy," in Democracy and Difference: Contesting the Boundaries of the Political, ed. Seyla Benhabib (Princeton, N.J. : Princeton University Press, 1996), 120 - 135; and Aletta J. Norval, Aversive Democracy: Inheritance and Originality in the Democratic Tradition (Cambridge: Cambridge University Press, 2007).

Nicole Curato, John S. Dryzek, Selen A. Ercan,

${ }^{6}$ John S. Dryzek and Simon J. Niemeyer, "Reconciling Pluralism and Consensus as Political Ideals," American Journal of Political Science 50 (3) (2006): 634 - 649.

37 Carole Pateman, "Participatory Democracy Revisited," Perspectives on Politics 10 (1) (2012): 8.

${ }^{8}$ John S. Dryzek and Alex Y. Lo, "Reason and Rhetoric in Climate Communication," Environmental Politics 24 (1) (2015): $1-16$.

39 Pateman, "Participatory Democracy Revisited," 10.

40 Lucio Baccaro, André Bächtiger, and Marion Deville, "Small Differences that Matter: The Impact of Discussion Modalities on Deliberative Outcomes," British Journal of Political Science 46 (3) (2016).

${ }^{41}$ Robert E. Goodin and Simon J. Niemeyer, "When Does Deliberation Begin? Internal Reflection versus Public Discussion in Deliberative Democracy," Political Studies 51 (4) (2003): 627 - 649.

42 Bernard Manin, “On Legitimacy and Political Deliberation,” Political Theory 15 (3) (1987):338- 368.

43 See also Simon Niemeyer and John S. Dryzek, “The Ends of Deliberation: Metaconsensus and Intersubjective Rationality as Deliberative Ideals," Swiss Political Science Review 13 (4) (2007): $497-526$.

44 Simon J. Niemeyer, “When Does Deliberation Really Begin?” working paper series (Canberra, Australia: Centre for Deliberative Democracy and Global Governance, 2016).

45 Cass R. Sunstein, “Deliberative Trouble: Why Groups Go to Extremes,” Yale Law Journal 110 (1) (2000): $71-119$.

46 James Fishkin, When the People Speak:Deliberative Democracy and Public Consultation (Oxford: Oxford University Press, 2009), 131-132.

47 Christopher F. Karpowitz, Raphael Chad, and Allen S. Hammond, "Deliberative Democracy and Inequality: Two Cheers for Enclave Deliberation among the Disempowered," Politics \& Society 37 (4) (2009): $576-615$.

48 Kimmo Grönlund, Herne Kaisa, and Maija Setälä, “Does Enclave Deliberation Polarize Opinions?" Political Behavior 37 (4) (2015): 995-1020.

49 Arend Lijphart, Democracy in Plural Societies: A Comparative Exploration (New Haven, Conn. : Yale University Press, 1977).

50 Ian O’Flynn, “Divided Societies and Deliberative Democracy,” British Journal of Political Science 37 (4) (2007): $731-751$.

${ }^{51}$ Robert C. Luskin, Ian O’Flynn, James S. Fishkin, and David Russell, “Deliberating across Deep Divides," Political Studies 62 (1) (2014): 117.

52 Bora Kanra, Islam, Democracy, and Dialogue in Turkey: Deliberating in Divided Societies (Aldershot, United Kingdom: Ashgate, 2009); and George Vasilev, Solidarity across Divides: Promoting the Moral Point of View (Edinburgh : Edinburgh University Press, 2015).

53 John S. Dryzek, "Handle with Care: The Deadly Hermeneutics of Deliberative Instrumentation," Acta Politica 40 (2) (2005): 197 - 211; and Selen A. Ercan, Carolyn M. Hendriks, and John Boswell, "Studying Public Deliberation After the Systemic Turn : The Crucial Role for Interpretive Research," Politics \& Policy 45 (2) (2017): 195 - 218.

54 Laura W. Black, Stephanie Burkhalter, John Gastil, and Jennifer Stromer-Galley, "Methods for Analyzing and Measuring Group Deliberation," in The Sourcebook of Political Communication 
Twelve Key Findings in

Deliberative Democracy Research
Research: Methods, Measures, and Analytical Techniques, ed. R. Lance Holbert (New York: Routledge, 2009), 323-345.

55 See, for example, Katharina Holzinger, "Kommunikationsmodi und Handlungstypen in den Internationalen Beziehungen. Anmerkungen zu einigen irreführenden Dichotomien," Zeitschrift Für Internationale Beziehungen 8 (2) (2001): 243-286; Steiner et al., Deliberative Politics in Action; and Niemeyer, "The Emancipatory Effect of Deliberation."

${ }^{56}$ Carolyn M. Hendriks, "Praxis Stories: Experiencing Interpretive Policy Research," Critical Policy Analysis 1 (3) (2007): 278 - 300.

57 John Boswell, Carolyn M. Hendriks, and Selen A. Ercan, "Message Received? Examining Transmission in Deliberative Systems," Critical Policy Studies 10 (3) (2016): 263-283; and Ercan et al., "Studying Public Deliberation After the Systemic Turn." 